ВАНГОРОДСКАЯ Светлана Анатольевна - кандидат социологических наук, доцент; доцент Белгородского государственного национального исследовательского университета; доцент кафедры социальных технологий Института экономики и управления (308015, Россия, г. Белгород, ул. Победы, 85; Vangorodskaya@bsu.edu.ru)

ЗАХАРОВ Виктор Михайлович - доктор социологических наук, профессор Белгородского государственного национального исследовательского университета; директор Института экономики и управления (308015, Россия, г. Белгород, ул. Победы, 85; zakharov@bsu.edu.ru)

БАБИНЦЕВ Валентин Павлович - доктор философских наук, профессор Белгородского государственного национального исследовательского университета, профессор кафедры социальных технологий Института экономики и управления (308015, Россия, г. Белгород, ул. Победы, 85; babintsev@ bsu.edu.ru)

\title{
РЕГИОНАЛЬНЫЕ ПРОГРАММЫ ПО ОХРАНЕ ЗДОРОВЬЯ: ПРОБЛЕМЫ РЕАЛИЗАЦИИ И ОЦЕНКИ
}

\begin{abstract}
Аннотация. В статье рассматриваются основные проблемы реализации и оценки региональных программ и проектов по охране здоровья населения. Авторы выделяют основные факторы, детерминирующие потенциал региональных профилактических программ в плане формирования оптимальных моделей самосохранительного поведения, предлагают количественные и качественные показатели, призванные усовершенствовать процедуру оценки эффективности региональных программ и концепций по охране здоровья. Авторы приходят к выводу о необходимости применения комплексного подхода для повышения эффективности реализации региональных программ в сфере здравоохранения.

Ключевые слова: государственная политика в сфере здравоохранения, региональные профилактические программы, эффективность региональных программ, охрана здоровья, самосохранительное поведение, самосохранительные установки
\end{abstract}

$\mathrm{K}$ ризисное состояние системы охраны здоровья населения в России требует разработки и реализации мер, которые не только направлены на решение ситуативных задач, но и одновременно ориентированы на перспективу. Это делает актуальной проблему программно-целевого управления сферой здравоохранения.

Важность принятия и реализации программ по охране здоровья населения, популяризации здорового образа жизни постоянно подчеркивается на самом высоком уровне. Так, в ходе выступления на заседании Совета при Президенте РФ по стратегическому развитию и приоритетным проектам, состоявшегося в Кремле 21 марта 2017 г., президент РФ В.В. Путин отметил: «За последние годы в сфере здравоохранения нам удалось добиться существенных изменений к лучшему... чтобы ситуация и дальше развивалась в нужном нам ключе, предстоит создать действительно современную систему здравоохранения... Важно не только качество лечения, но и профилактика заболевания, популяризация здорового образа жизни. Здесь также нужно продолжать активную работу» ${ }^{1}$. Это же подчеркнула и министр здравоохранения РФ В. Скворцова, отчитываясь о деятельности министерства за 2017 г.: «...самой эффективной мерой для снижения смертности и увеличения продолжительности жизни является профилактика заболеваний»².

\footnotetext{
1 Заседание Совета по стратегическому развитию и приоритетным проектам. - Президент России: официальный сайт. Доступ: http://www.kremlin.ru/events/president/news/54079 (проверено 17.03.2019).

2 Отчет министра здравоохранения В.Скворцовой за 2017 г. - Sarmedinfo 2018: информационный портал. Доступ: http://www.sarmedinfo.ru/official/2018/04/11/otchet-ministr/ (проверено 12.03.2019).
} 
Исходя из этого, основной акцент в деятельности государства по охране здоровья граждан переносится в последние годы на разработку и реализацию комплексных программ профилактики (программа «Здоровье здоровых», национальный проект «Здоровье» и т.д.), направленных на сокращение потребления алкоголя и табака, популяризацию занятий физической культурой и спортом и т.д. С 1 января 2019 г. в России началась реализация национального проекта «Демография», включающего в себя 5 федеральных проектов, в т.ч. проект «Укрепление общественного здоровья», предполагающий формирование системы мотивации граждан к здоровому образу жизни ${ }^{1}$. На официальном сайте Министерства здравоохранения РФ создан портал «Здоровая Россия» 2 , посвященный здоровому образу жизни, а также работает круглосуточный бесплатный анонимный портал доверия и психологической помощи для детей, подростков и их родителей ${ }^{3}$.

Одной из основных концепций охраны здоровья, положенных в основу формирования государственной политики в сфере здравоохранения, является концепция региональных систем здравоохранения, базирующаяся на предположении, что регион является средоточием основных потребностей населения и имеет необходимые ресурсы для обеспечения гарантий населению в сфере охраны здоровья [Арбитайло 2014: 4].

Действительно, отдельные примеры реализации региональных профилактических программ показали их эффективность в плане формирования оптимальных моделей самосохранительного поведения. В качестве примеров успешной реализации межведомственных проектов на территории Центрального федерального округа можно привести проект «Живи долго!» (реализуется на территории Воронежской обл. с 2014 г.), проект «Управление здоровьем» (осуществляется в Белгородской обл. с мая 2016 г.), а также реализуемый с апреля 2017 г. в Липецкой обл. долгосрочный приоритетный проект «Здоровый регион».

Однако сам по себе факт разработки и практического запуска программы не является основанием для признания ее успешной. Еще менее показательны суждения о ней чиновников, нередко определяющиеся их личными или корпоративными интересами.

В то же время процесс анализа и оценки реализации подобных проектов является необходимым компонентом стратегического управления системой здравоохранения, обеспечивающим прозрачность и подотчетность управленческих процессов и позволяющим представить общую картину выполнения государственных обязательств в сфере охраны здоровья. Между тем сложность оценки обусловлена не только разным уровнем социально-экономического развития регионов, спецификой демографической ситуации, а также объемом и эффективностью распределения финансовых и иных средств, предусмотренных на реализацию подобных программ. При этом речь идет не только о наличии этих средств, но и об их доступности и эффективности использования.

Необходимо также учитывать тот факт, что потенциальные возможности региональных концепций и программ в значительной степени определяются культурно-историческими и религиозными особенностями коллективного сознания жителей отдельных территорий. По справедливому замечанию экспертов, «стратегия, в данном случае демографического развития, не может быть обоснована лишь на основе анализа формальных показателей, характеризую-

\footnotetext{
1 Национальный проект «Демография». - Министерство труда и социальной защиты Российской Федерации: официальный сайт. Доступ: https://rosmintrud.ru/ministry/programms/demography (проверено 09.07.2019).

2 http://www.takzdorovo.ru (проверено 09.07.2019).

3 http://telefon-doveria.ru (проверено 09.07.2019).
} 
щих рождаемость, смертность и миграцию населения. Нужны другие содержательные оценки, учитывающие исторические, геополитические, природногеографические и иные особенности» [Демография... 2014].

Например, республики Северного Кавказа, традиционно занимающие верхние строчки общероссийских рейтингов по высокой продолжительности жизни и низкой приверженности вредным привычкам (в т.ч. по употреблению крепкого алкоголя), снискали себе славу самых благополучных в демографическом отношении регионов не столько благодаря реализации программных мероприятий, сколько вследствие культурно-исторических особенностей, детерминирующих жизненный уклад и привычки большей части населения.

Исходя из этого, при разработке и реализации региональных профилактических программ необходимо учитывать весь комплекс особенностей, характерных для конкретной территории, - социально-экономических, финансовых, культурно-исторических, гендерных, возрастных и даже климатических. Что касается последних, то их влияние на эффективность реализации отдельных мер также традиционно недооценивается. Между тем, по данным ряда исследований, данный фактор играет важную роль, особенно в детерминации алкогольной заболеваемости и смертности. Так, например, согласно модели общественного здоровья, предложенной И.Н. Гурвичем, именно климатические условия выступают в качестве одного из факторов различий в уровне алкоголизации населения [Гурвич 1998]. Из исследований последних лет значительный интерес представляют результаты контент-анализа региональных программ 2015-2016 гг. по противодействию потреблению алкоголя, отраженные в статье Ю.Ю. Беловой «Модели социальной превенции алкоголизации населения в регионах России с различными климатическими условиями» [Белова 2018]. Констатируя наличие прямой корреляции между климатическими условиями территорий и региональными паттернами потребления алкоголя, автор рекомендует региональным властям учитывать «пространственный градиент процесса алкоголизации населения в России... при внедрении превентивных программ и проектов» [Белова 2018: 334].

Из всего многообразия факторов, оказывающих влияние на потенциальные возможности региональных концепций и программ в плане формирования оптимальных моделей самосохранительного поведения, наиболее важными, на наш взгляд, являются следующие.

1. Экономические возможности, которыми располагает регион и которые напрямую коррелируют с резервами роста продолжительности жизни населения. По мнению экспертов, именно экономические возможности региона «определяют условия жизни населения, а следовательно в значительной мере и образ жизни, и характер самосохранительного поведения людей. Экономические возможности формируют инвестиции в охрану здоровья населения и все области социальной инфраструктуры, ответственные за здоровье людей» [Демография... 2014]. При этом если реализация политики по охране здоровья населения в экономически неблагополучных регионах должна в первую очередь предполагать улучшение экономических показателей и качества жизни населения (поскольку группы с низкими доходами являются наиболее уязвимыми в плане риска возникновения различных заболеваний), то в более благополучных регионах на первый план выходит рациональное использование имеющихся возможностей. С другой стороны, те же республики Северного Кавказа являют собой пример территорий, которые добились высоких показателей здоровья и продолжительности жизни населения при ограниченных экономических возможностях, что позволяет рекомендовать этот опыт для изу- 
чения и внедрения в практику более неблагополучных в экономическом отношении регионов России.

2. Ресурсное обеспечение реализации программных мероприятий. Эффективность реализации программ, направленных на сохранение и укрепление здоровья населения, в значительной степени связана с ресурсным (прежде всего, финансовым) обеспечением. Так, согласно рекомендациям Всемирной организации здравоохранения, только при условии финансирования профилактической деятельности из расчета не менее 5-7 руб. на одного жителя региона можно сформировать в общественном сознании установки на самосохранительное поведение [Стародубов, Соболева, Савченко 2016: 940]. При этом, по оценкам экспертов, ни в одном из регионов РФ (не исключая ЦФО) данный показатель не достигает указанного уровня. В частности, в 2014 г. на реализацию программ в Центральном федеральном округе было получено 0,4 руб. бюджетных средств (из расчета на 1 чел.), из них на реализацию целевых программ - 0,1 руб. [Стародубов, Соболева, Савченко 2016: 940]. При таком уровне финансирования говорить об эффективности проводимых мероприятий не представляются возможным.

По мнению экспертов, проблема недостаточного финансирования является основной проблемой низкой эффективности и результативности региональных программ, поскольку приводит не только к «нерентабельной и убыточной реализации проектов, омертвлению уже вложенных финансовых ресурсов, но и к увеличению остроты проблемных ситуаций, на разрешение которых ориентированы данные программы» [Курченков, Коробкина, Калмыкова 2016: 43]. Вместе с тем было бы наивным полагать, что стоящие перед регионами проблемы укрепления и охраны здоровья населения могут быть решены исключительно за счет оптимизации финансирования. Региональные бюджеты попросту не рассчитаны на радикальное изменение ситуации в сфере здравоохранения.

По словам министра здравоохранения РФ В. Скворцовой, износ основных фондов в отрасли превышает 50\%, более половины населения страны не удовлетворены качеством медицинского обслуживания, более $40 \%$ медицинских организаций нуждаются в комплексном переоснащении, а более $17 \%$ медучреждений требуют капитального ремонта ${ }^{1}$. Оценивая масштаб необходимых средств, Г.Э. Улумбекова и Н.Ф. Прохоренко приводят в пример один из наиболее успешных российских регионов, которому (по данным ВШОУЗ) требуется минимум 20-25 млрд руб. на обновление основных средств медицинских организаций. Естественно, в менее благополучных регионах этот дефицит будет еще больше [Улумбекова, Прохоренко 2018: 29]. Дополнительную остроту ситуации придает тот факт, что существенная часть расходов на получение медицинских услуг ложится на плечи самого населения. Анализируя данные статистики, согласно которым россияне в настоящее время оплачивают порядка $35 \%$ затрат на здравоохранение, эксперты заявляют, что «вынуждать население увеличивать эту долю не просто некорректно, но и безответственно», а также прогнозируют возможный всплеск социального недовольства людей, поставленных в ситуацию невозможности получить бесплатно и одновременно физической невозможности оплатить требуемую медицинскую помощь» [Улумбекова, Прохоренко 2018: 28].

В этих условиях изменение ситуации возможно лишь путем привлечения дополнительных внебюджетных средств такими способами, которые могли бы

\footnotetext{
1 Открытая экономика. ГЧП - и новая модель здравоохранения. - Научно-образовательный портал IQ. Национальный исследовательский университет «Высшая школа экономики»: сайт. Доступ: https://iq.hse. ru/news/177671472.html (проверено 09.07.2019).
} 
удовлетворить интересы обеих сторон. Успешный опыт регионов и мнения экспертов доказывают, что на сегодняшний день существует множество способов эффективной реализации механизма государственно-частного партнерства при обеспечении населения качественными и доступными медицинским услугами в рамках регионального законодательства.

В послании Федеральному собранию от 1 марта 2018 г. президент РФ В. Путин заявил, что в 2019-2024 гг. на развитие здравоохранения из всех источников будет направлено более 4\% ВВП, а «общие объемы расходов на здравоохранение должны увеличиться вдвое» ${ }^{1}$. В частности, в рамках реализации государственной программы «Развитие здравоохранения» на мотивацию населения к здоровому образу жизни, правильному питанию и отказу от вредных привычек предполагается направить 2,8 млрд руб. При этом, по мнению руководителя Высшей школы организации и управления здравоохранением (ВШОУЗ) Г.Э. Улумбековой, само по себе увеличение финансирования даст ожидаемый результат только в том случае, если распоряжение дополнительными средствами будут осуществлять грамотные руководители, владеющие современными управленческими технологиями и направляющие основные усилия на решение главной управленческой задачи - восстановление доверия и взаимного уважения между врачами и пациентами [Улумбекова 2018: 16].

3. Информационное обеспечение реализации концепций и программ, в первую очередь в части предоставления достоверных статистических данных о причинах смертности населения. Распространившаяся в последние годы в регионах практика «перебрасывания» смертей с основных групп причин смертности в группу «неточно обозначенных состояний» не только поставила под сомнение реальную динамику смертности в регионах, но и привела к смещению приоритетов в деятельности региональных органов власти [Вангородская 2016]. По мнению экспертов, именно «вопросы качества диагностики причин смерти - это вопрос реальной политики в сфере здравоохранения и ее адекватного финансирования» [Демография... 2014].

4. Самосохранительные установки большей части населения российских регионов. Традиционные для массового сознания жителей России патерналистские ожидания и нежелание нести личную ответственность за состояние своего здоровья привели к тому, что, несмотря на ряд позитивных изменений в региональных системах здравоохранения, демографические показатели в субъектах РФ часто остаются неудовлетворительными. Сдерживающими факторами являются поздняя обращаемость граждан за медицинской помощью, слабая мотивация к ведению здорового образа жизни, приверженность к вредным привычкам, подрывающим здоровье. Так, согласно данным массового опроса, проведенного нами осенью 2018 г. в 9 регионах Центральной России $(N=1067)$, признавая здоровье в качестве главной жизненной ценности (это отметили $52,7 \%$ опрошенных), более трети респондентов $(36,3 \%)$ признались, что не уделяют его сохранению и укреплению должного внимания, обращаются к врачам только в случае крайней необходимости $(44,4 \%)$ и не предпринимают сознательных усилий для увеличения продолжительности жизни $(36,4 \%)$.

Анализируя возможности региональных концепций охраны здоровья и комплексных профилактических программ в плане формирования оптимальных моделей самосохранительного поведения, нельзя не учитывать также разное смысловое наполнение данных документов. Это особенно важно еще и потому, что, по оценкам экспертов, в практике регионального нормотворчества наблю-

1 Послание Президента РФ Федеральному Собранию. 1 марта 2018 года. - Президент России: официальный сайт. Доступ: http://www.kremlin.ru/events/president/news/56957 (проверено 12.03.2019). 
дается не только «смешение концептуальных вопросов с программными», но и «механическое перенесение положений федеральной концепции в концепции демографической политики субъектов Российской Федерации» [Демография... 2014].

В работе В.В. Курченкова к числу причин низкой эффективности областных целевых программ отнесены несоответствие целевых показателей конкретных программ долгосрочным целям социально-экономического развития; недостаточность ресурсной базы, методов и инструментов реализации региональных целевых программ; отсутствие единой методики проведения сравнительного анализа оценки эффективности региональных целевых программ [Курченков, Коробкина, Калмыкова 2016: 40]. Кроме того, по мнению экспертов, для большинства программ характерно наличие абстрактных формулировок, смысл которых может трактоваться достаточно широко и позволяет использовать для достижения целевых показателей достаточно широкий спектр видов деятельности, отсутствие четко сформулированной цели, соответствующей условиям и возможностям конкретного региона, а также отсутствие системности и комплексности, обусловленное недостаточным уровнем «демографической грамотности их составителей» [Бобков и др. 2013: 10].

Существенный интерес представляет классификация таких исследователей, как А.А. Божья-Воля и Е.Ю. Мясникова, которые, ссылаясь на ряд зарубежных исследований, выделили 7 парадоксов, присутствующих в программноцелевом управлении и снижающих его эффективность: «туннельное видение», «близорукость», «тяготение к критериям», «введение в заблуждение», «неверное толкование», «субоптимизацию» и «азартную игру» [Божья-Воля, Мясникова 2016: 101]. Кроме того, согласно Т.С. Соловьевой, которая ссылается на мнение экспертов, применение программно-целевых методов «носит формальный характер: на практике до сих пор преобладают традиционные методы управления, которые подразумевают не достижение определенных целей, а контроль за выполнением плановых мероприятий» [Соловьева 2017: 152].

Сложность разработки индикаторной модели оценки потенциальных возможностей региональных концепций и комплексных профилактических программ заключается, кроме всего прочего, в неоднозначности количественных показателей и критериев и их разнонаправленной динамике. При этом анализ результатов программ в отдельных регионах (как по отдельным показателям, так и по совокупному результату) позволяет выявить особенности и потенциальные возможности каждого из выбранных в качестве объекта исследования регионов в плане формирования оптимальных моделей самосохранительного поведения населения.

В качестве количественных показателей, используемых для оценки эффективности отдельных региональных программ и концепций по охране здоровья, могут применяться как традиционные, так и нетрадиционные показатели и критерии оценки. В качестве количественных показателей можно использовать:

1) коэффициенты преждевременной смертности населения от основных управляемых причин на 100 тыс. чел. населения;

2) заболеваемость (в первую очередь социально значимыми болезнями) с впервые в жизни установленным диагнозом (в соответствии с основными группами причин смертности, на 100 тыс. чел. населения);

3) показатель ожидаемой продолжительности жизни при рождении, лет;

4) распространенность потребления алкогольной продукции (в перерасчете на абсолютный алкоголь);

5) распространенность потребления табака среди взрослого населения, детей и подростков; 
6) число посещений гражданами медицинских учреждений с профилактическими целями;

7) число прошедших диспансеризацию и посетивших центры здоровья (динамика в сравнении с предыдущими периодами);

8) число сообщений в СМИ по здоровьесберегающей тематике и т.д.

К числу качественных показателей могут быть отнесены:

1) сокращение несправедливости в отношении здоровья (целевой ориентир, относящийся к социальным детерминантам);

2) повышение удовлетворенности граждан уровнем получения медицинских услуг (по результатам выборочных социологических исследований);

3) позитивные изменения результатов опросов целевых аудиторий об отношении к своему здоровью;

4) позитивные изменения результатов опросов населения о деятельности государства в части реализации проектов по охране здоровья;

5) положительная динамика тональности сообщений в средствах массовой информации о реализации региональных проектов по охране здоровья;

6) повышение удовлетворенности населения развитием физкультурно-спортивной инфраструктуры и качеством проведения физкультурно-оздоровительных и спортивных мероприятий и т.д.

На наш взгляд, использование совокупности данных показателей и индикаторов будет особенно результативным в разрезе сравнительного анализа региональной статистки, т.к. позволит диагностировать асимметрию в показателях здоровья населения и степень сформированности оптимальных моделей самосохранительного поведения.

Серьезной проблемой является сложность оценки вклада конкретных программных мероприятий в положительную динамику демографических показателей в регионе. Причины этого кроются, во-первых, в существовании множества внешних факторов, оказывающих влияние на демографические показатели. Во-вторых, большое число и разнообразие целевых программ на территории каждого региона делают оценку вклада каждой из них в регулирование демографических показателей методически и технически сложной. В-третьих, ввиду наличия большого числа исполнителей программ проблематично оценить вклад каждого из ведомств в реализацию программных мероприятий. Все это в совокупности практически сводит к нулю возможность «доказательного выявления причинно-следственной связи между реализуемыми мерами (и соответствующими затратами) и полученными результатами (конкретными изменениями в демографической ситуации)» [Бобков и др. 2013: 15]. А это, в свою очередь, делает проблематичным корректировку среднесрочных графиков выполнения мероприятий программ, а также планов действий отдельных структур и исполнителей, участвующих в реализации проектов и программ.

Одним из вариантов решения проблемы может стать проведение демографической экспертизы текстов программ как на стадии разработки, так и на всех этапах реализации как инструмента оценки их качества и результативности [Бобков и др. 2013: 13]. Кроме того, обязательным этапом, предваряющим внесение отдельных мероприятий в состав региональных профилактических программ, должен стать комплексный научный анализ факторов, оказывающих влияние на показатели заболеваемости и смертности в конкретном регионе. И в первую очередь этот анализ должен учитывать медико-демографические показатели отдельных возрастных групп населения с целью определения их вклада в динамику коэффициентов смертности от разных классов причин. Так, например, в подавляющем большинстве российских регионов наблюдается катастрофическая ситуация со смертностью мужчин младших трудоспособных возрас- 
тов от внешних причин. Следовательно, значительная часть мер, запланированных в рамках реализации региональных программ, должна ориентировать внимание различных структур на работу именно с представителями данной категории населения.

При реализации программ необходимо учитывать международный опыт, а также более активно использовать успешную практику российских регионов в реализации проектов и программ, направленных на формирование оптимальных стратегий поведения в отношении своего здоровья. Сочетая как «жесткие», так и «мягкие» инструменты воздействия на индивидуальное и общественное поведение, необходимо основной упор сделать на внедрение немедицинских моделей формирования самосохранительных установок (например, на создание идеологии общественного поощрения индивидуальных практик ведения здорового образа жизни), широко используемых в зарубежной и отечественной практике и уже доказавших свою эффективность. Только комплексный подход, основанный на интеграции научных разработок и практических методов управления и подкрепленный соответствующей финансовой базой, позволит поднять эффективность реализации региональных программ в сфере здравоохранения на принципиально новый уровень и добиться продвижения в деле улучшения показателей здоровья и увеличения продолжительности жизни населения России.

Исследование выполнено в рамках государственного задания НИУ «БелГУ» на 2017 год, проект № 28.7195.2017/БЧ «Риски и тренды самосохранительного поведения населения центральных регионов Российской Федерации».

\section{Список литературы}

Арбитайло И.Я. 2014. Эффективность региональной системы здравоохранения. - Современные проблемы науки и образования: электронный научный журнал. № 5. Доступ: https://science-education.ru/ru/article/view?id=15169 (проверено 13.03.2019).

Белова Ю.Ю. 2018. Модели социальной превенции алкоголизации населения в регионах России с различными климатическими условиями. - Регионология. T. 26. № 2. С. 314-337.

Бобков В.Н., Елизаров В.В., Джанаева Н.Г., Данилова Н.А., Маликов Н.С., Синица А.Л. 2013. Методологические основы разработки региональных программ демографического развития с учетом региональных особенностей (на примере Дальневосточного федерального округа). - Уровень жизни населения регионов России. № 1. С. 10-17.

Божья-Воля А.А., Мясникова Е.Ю. 2016. Преодоление «парадоксов результативности» при реализации государственных программ Пермского края. - Ars Administrandi (Искусство управления). № 1. С. 99-112.

Вангородская С.А. 2016. Смерть от старости: результат демографической политики или инструмент имитационной деятельности органов власти? Власть. Т. 24. № 5. С. 94-102.

Гурвич И.Н. 1998. Социальный контроль алкоголизации. - Социальный контроль над девиантностью. СПб: Филиал ИС РАН, Балтийский институт экологии, политики и права. С. 32-45.

Демография для практических работников: методические рекомендации для специалистов органов исполнительной власти субъектов РФ (под ред. Л.Л. Рыбаковского). 2014. М.: Экон-информ. 254 с.

Курченков В.В., Коробкина Т.В., Калмыкова Т.Н. 2016. Оценка эффективно- 
сти реализации региональных и муниципальных целевых программ. - Вестник Волгоградского государственного университета. Сер. 3. Экономика, Экология. № 3(36). C. 39-45.

Соловьева Т.С. 2017. Индикативная оценка результативности программноцелевого управления образовательными системами. - Проблемы развития территории. Вып. 2(88). С. 149-164.

Стародубов В.И., Соболева Н.П., Савченко Е.Д. 2016. Совершенствование деятельности центров здоровья. - Казанский медицинский журнал. Т. 97. № 6. С. 939-944.

Улумбекова Г.Э. 2018. Здравоохранение России: 2018-2024 гг. Что надо делать? - ОРГЗДРАВ: новости, мнения, обучение. Вестник ВШОУЗ. № 1(11). С. 9-16.

Улумбекова Г.Э., Прохоренко Н.Ф. 2018. Доклад Центра стратегических разработок «Здравоохранение: необходимые ответы на вызовы времени». Основные впечатления. - ОРГЗДРАВ: новости, мнения, обучение. Вестник ВШОУЗ. № 1(11). C. 27-29.

VANGORODSKAYA Svetlana Anatol'evna, Cand.Sci. (Soc.), Associate Professor; Associate Professor of the Chair of Social Technologies, Institute of Economics and Management, Belgorod State National Research University (85 Pobedy St, Belgorod, Russia, 308015; Vangorodskaya@bsu.edu.ru)

ZAKHAROV Viktor Mikhailovich, Dr.Sci. (Soc.), Professor of the Chair of Social Technologies, Institute of Economics and Management, Belgorod State National Research University (85 Pobedy St, Belgorod, Russia, 308015; zakharov@ bsu.edu.ru)

BABINTSEV Valentin Pavlovich, Dr.Sci. (Philos.), Professor of the Chair of Social Technologies, Institute of Economics and Management, Belgorod State National Research University (85 Pobedy St, Belgorod, Russia, 308015; babintsev@ bsu.edu.ru)

\title{
REGIONAL PROGRAMS FOR HEALTH: ISSUES OF IMPLEMENTATION AND EVALUATION
}

\begin{abstract}
The article deals with the main problems of implementation and evaluation of regional programs and projects for the protection of public health. The authors show that the creation of an effectively functioning system of public health protection is an important element of the state policy of the federal and regional authorities, and the main emphasis in the activities of the state is made in recent years on the development and implementation of comprehensive prevention programs. The article indicates that the potential of regional concepts and programs are largely determined by the culturalhistorical, age-sexual, religious and other features that characterize the population of individual territories and identify the main factors determining the potential of regional prevention programs in terms of the formation of optimal models of selfpreservation behavior. The authors propose quantitative and qualitative indicators to improve the procedure for assessing the effectiveness of regional health programs and concepts and show the necessity to apply an integrated approach to improve the effectiveness of the implementation of regional programs in the field of health.

Keywords: public health policy, regional prevention programs, effectiveness of regional programs, health protection, selfpreservation behavior, self-preservation settings
\end{abstract}

